\title{
A study of prevalence of thyroid dysfunction in abnormal uterine bleeding
}

\author{
Aditi Rai*, Sapna Raina
}

Department of Obstetrics and Gynecology, Mazumdar Shaw Hospital, Bengaluru, Karnataka, India

Received: 04 May 2020

Accepted: 30 May 2020

\section{*Correspondence:}

Dr. Aditi Rai,

E-mail: aditirai004@gmail.com

Copyright: (C) the author(s), publisher and licensee Medip Academy. This is an open-access article distributed under the terms of the Creative Commons Attribution Non-Commercial License, which permits unrestricted non-commercial use, distribution, and reproduction in any medium, provided the original work is properly cited.

\begin{abstract}
Background: Abnormal uterine bleeding (AUB) is one of the most frequent presentation to gynecology OPD. AUB is a common but complicated clinical presentation and occurs in $15-20 \%$ of women between menarche to menopause and significantly affects the women's health. Thyroid disorders are more common in women than in men and cause abnormal sexual development, menstrual irregularity, infertility and premature menopause. Objective of this study was to estimate the prevalence of thyroid disorders in women in reproductive age group with AUB.

Methods: A hospital based prospective cross sectional observational study was carried out in department of obstetrics and gynecology, Mazumdar-Shaw Cancer and Medical Center and Narayana Hrudayalaya Hospital at Narayana Health City, Bangalore with abnormal uterine bleeding during the period of 2 years (December 2015 to November 2017), total 153 patients were included in the study. All women with AUB in reproductive age group were included. Diagnosed cases of ovarian cyst, uterine fibroid, polyp, adenomyosis, endometriosis and malignant (endometrial and cervical) tumors were excluded. Women who are on drugs or hormone therapy (for past 3 months. IUCD users/oral contraceptives pill user. Patients with known case of thyroid disorder, carcinoma thyroid patients with history of coagulation disorder, liver disorder, renal disorder, tuberculosis.

Results: A total $\mathrm{N}=115(75.2 \%)$ of patients who took part in this study had euthyroid status. The estimated prevalence of thyroid dysfunction was $24.9 \%$. Out of which $n=22(14.4 \%)$ had subclinical hypothyroidism, $n=14(9.2 \%)$ had overt hypothyroidism, $\mathrm{n}=2(1.3 \%)$ had hyperthyroidism. The most common thyroid dysfunction amongst the study group was noted to be subclinical hypothyroidism (14.4\%).

Conclusions: There is a high prevalence of thyroid disorders in cases which are clinically diagnosed as AUB. TSH is most sensitive test in detecting thyroid dysfunction. Subclinical cases need to be treated. Hence thyroid function evaluation should be made mandatory in cases of AUB to detect thyroid dysfunction.
\end{abstract}

Keywords: Abnormal uterine bleeding, Anovulatory, Hyperthyroidism, Hypothyroidism, Leiomyoma, Menorrhagia, Polyp adenomyosis

\section{INTRODUCTION}

Abnormal uterine bleeding (AUB) is a term used to describe any type of bleeding that does not fall within the normal range for amount, frequency, duration and cyclicity. AUB is one of the most frequent presentation to gynecology OPD. AUB is a common but complicated clinical presentation and occurs in $15-20 \%$ of women between menarche to menopause and significantly affects the women's health.

Dysfunctional uterine bleeding is defined as abnormal bleeding from uterus in absence of organic disease of the genital tract. A normal cycle starts when pituitary follicle stimulating hormone induces ovarian follicles to produce estrogen. Estrogen stimulates proliferation of the 
endometrium. A luteinizing hormone surge prompts ovulation, the resultant corpus luteum produces progesterone, inducing a secretory endometrium. Any disruption in the normal physiology or anatomic changes in the endometrium results in abnormal uterine bleeding. Initially AUB was broadly divided into two categories $\rightarrow$ anovulatory and ovulatory, but now after November 2010 the International federation of gynaecology and obstetrics formally accepted a new classification system for causes of AUB in reproductive years. The system is based on acronym PALM-COEIN.

PALM (structural causes) $\rightarrow$ polyps, adenomyosis, leiomyoma, malignancy and hyperplasia. COEIN (nonstructural causes) $\rightarrow$ coagulopathy, ovulatory disorders, endometrial causes, iatrogenic, not classified. ${ }^{2}$

Out of all the etiologies, age variations and clinical presentations - thyroid dysfunction (subclinical or overt) has been found to have a significant correlation with nonstructural causes of AUB. Hyperthyroidism and hypothyroidism are both associated with menstrual abnormalities. One of the explanations is activity of thyroid is closely linked with the process of ovarian maturation. The thyroid gland is itself dependent on direct and indirect stimulation from the ovary to discharge its own function. After excluding the structural causes of AUB most cases are associated with failure of ovulation and consequent hormonal imbalance. Ovarian dysfunction may be caused by either a primary defect or pathological lesion within the ovary itself or may be secondary to malfunction of other endocrine glands notably in hypothalamus, pituitary and thyroid gland. ${ }^{3}$

Thyroid disorders are more common in women than in men and cause abnormal sexual development, menstrual irregularity, infertility and premature menopause. ${ }^{4}$ Menstrual abnormality precedes the onset of clinically overt hypothyroidism or hyperthyroidism.

Menorrhagia and polymenorrhagia are more common but amenorrhea is rare. Both hypothyroidism and hyperthyroidism may result in menstrual disturbances. In hypothyroid, majority of subclinical hypothyroid cases easily pass unrecognized and the prevalence of hypothyroidism is as high as $9.5 \%$ in women. ${ }^{5}$ This may go unnoticed by unwary clinicians as these patients do not exhibit clinically overt physical symptoms and signs.

The menstrual pattern is influenced by thyroid hormones directly through impact on the ovaries and indirectly through impact on sex hormone binding globulin (SHBG), prolactin (PRL) and gonadotropin releasing hormones $(\mathrm{GnRH})$ secretion and coagulation factors. In women with hypothyroidism, TRH induced hyperprolactinemia alter the GnRH pulsatile secretion leading to defective or delay in $\mathrm{LH}$ response leading to luteal phase defect and subsequent anovulation. For proper production of progesterone, the synergistic effect of follicular stimulating hormones (FSH) mediated luteinizing hormones $(\mathrm{LH})$ receptor are important and they are directly influenced by thyroid hormones. Hypothyroidism also alters peripheral metabolism of estrogen by decreasing SHBG production leading to abnormal feedback at pituitary level. SHBG production increases in hyperthyroidism. The metabolism of estrogen is altered and peripheral conversion of androgens to estrogen is increased. Despite these metabolic changes, hyperthyroid women usually maintain ovulation, according to endometrial biopsies. ${ }^{6}$

\section{Aims}

To estimate the prevalence of thyroid disorders in women in reproductive age group with abnormal uterine bleeding (AUB).

\section{Objectives}

- To evaluate thyroid function tests in women with AUB.

- To assess the menstrual patterns and endometrial histological pattern in women with thyroid disorder.

\section{METHODS}

A hospital based prospective cross-sectional observational study was carried out in department of obstetrics and gynecology, Mazumdar-Shaw Cancer and Medical Center and Narayana Hrudayalaya Hospital at Narayana Health City, Bangalore with Abnormal uterine bleeding during the period of 2 years (December 2015November 2017), total 153 patients were included in the study.

\section{Inclusion criteria}

- All women with abnormal uterine bleeding in reproductive age group.

\section{Exclusion criteria}

- Diagnosed cases of ovarian cyst, uterine fibroid, polyp, adenomyosis, endometriosis and malignant (endometrial and cervical) tumors.

- Women who are on drugs or hormone therapy (For past 3 months)

- IUCD users/oral contraceptives pill user.

- Patients with known case of thyroid disorder, carcinoma thyroid

- Patients with history of coagulation disorder, liver disorder, renal disorder, tuberculosis

- Pregnant women, abortion within 3 months, Last child birth within 1 year.

\section{Methodology}

- The study protocol included a thorough history taking regarding age, menstrual pattern, onset, 
duration, quantity of bleeding and complaints related to thyroid dysfunction were to be noted in detail

- A thorough clinical examination including general physical examination, neck examination (especially thyroid gland), systemic and gynecologic examinations were to be carried out.

- All the recruited patients were to be subjected to routine investigations like hemoglobin, ESR, LFT, RBS, complete urine examination, urine for pregnancy test, bleeding time, clotting time, chest Xray, ultrasound abdomen and pelvis, pap smear, endometrial biopsy (in reproductive age group where endometrial thickness is more and to rule out endometrial pathology which is done by pipes canula).

Then all patients were subjected for free T3, totalT4 and TSH estimation in their sera. Levels were estimated by chemiluminescence immunoassay (CLIA) method for in vitro diagnostic use in the quantitative determination of T3, T4 and TSH estimation in serum using the ADVIA Centaur and ADVIA Centaur XP systems, in Biochemistry lab at Narayana Hrudayalaya Hospital.

\section{RESULTS}

The minimum age of the patient included in the study was 18 years and maximum age of the patient was 45 years with the maximum number of patients belonged to the age group $31-40$ years, $n=70$ cases $(45.8 \%)$ followed by $>40$ years, $n=60(39.2 \%)$.

Table 1: Distribution of patients according to age group.

\begin{tabular}{|lll|}
\hline Age groups (years) & No. of cases & Percentage \\
\hline$<20$ & 5 & $3.3 \%$ \\
\hline $21-30$ & 18 & $11.8 \%$ \\
\hline $31-40$ & 70 & $45.8 \%$ \\
\hline$>40$ & 60 & $39.2 \%$ \\
\hline Total & 153 & $100 \%$ \\
\hline
\end{tabular}

Table 2: Distribution of patients according to parity.

\begin{tabular}{|lll|}
\hline Parity & No. of cases & Percentage \\
\hline Nullipara & 10 & $6.5 \%$ \\
\hline 1 & 10 & $6.5 \%$ \\
\hline 2 & 100 & $65.4 \%$ \\
\hline$>3$ & 33 & $21.6 \%$ \\
\hline Total & 153 & $100 \%$ \\
\hline
\end{tabular}

In present study, in 153 cases of $A U B, n=10(6.5 \%)$ were nullipara and $\mathrm{n}=10(6.5 \%)$ patients were primiparous, $\mathrm{n}=133(87 \%)$ patients were multiparous. In this study maximum number of patients were multiparous.

In present study, $85.6 \%$ patients presented with menorrhagia, $7.2 \%$ patients presented with polymenorrhea, $5.9 \%$ patients presented with oligomenorrhea, $1.3 \%$ patients presented with polymenorrhagia. Most of the patients presented with complaint of menorrhagia.

Table 3: Distribution of patients according to bleeding pattern.

\begin{tabular}{|ll|l|}
\hline Type of bleeding & No. of cases & Percentage \\
\hline Menorrhagia & 131 & $85.6 \%$ \\
\hline Polymenorrhagia & 2 & $1.3 \%$ \\
\hline Oligomenorrhoea & 9 & $5.9 \%$ \\
\hline Polymenorrhoea & 11 & $7.2 \%$ \\
\hline Total & 153 & $100 \%$ \\
\hline
\end{tabular}

In present study, the prevalence of thyroid dysfunction in AUB was $24.9 \%$. The prevalence of hypothyroidism was $\mathrm{n}=36(23.6 \%)$, out of which subclinical hypothyroidism was $n=22(14.4 \%)$ and overt hypothyroidism was $n=14$ (9.2\%). $\mathrm{n}=2 \quad(1.3 \%)$ were hyperthyroid. The most common thyroid dysfunction amongst the study group was noted to be subclinical hypothyroidism (14.4\%).

Table 4: Distribution of patients according to thyroid dysfunction.

\begin{tabular}{|ll|l|}
\hline Thyroid status & No. of cases & Percentage \\
\hline Euthyroid & 115 & $75.2 \%$ \\
\hline Hypothyroid & 14 & $9.2 \%$ \\
\hline $\begin{array}{l}\text { Subclinical } \\
\text { hypothyroid }\end{array}$ & 22 & $14.4 \%$ \\
\hline Hyperthyroid & 2 & $1.3 \%$ \\
\hline Total & 153 & $100 \%$ \\
\hline
\end{tabular}

It was found that, out of 153 patients, $n=36$ (23.5\%) patients had hypothyroidism, $\mathrm{n}=14(9.1 \%)$ patients with overt hypothyroidism and $n=22(14.3 \%)$ patients with subclinical hypothyroidism. $\mathrm{n}=2$ patients were diagnosed with hyperthyroidism. $n=115$ patients were found to be euthyroid. Out of $n=14$ patients who had overt hypothyroidism, $\mathrm{n}=13(92.9 \%)$ patients presented with menorrhagia and $\mathrm{n}=1(7.1 \%)$ patients presented with polymenorrhea. Out of $n=22$ patients who were diagnosed to have subclinical hypothyroidism, following were the bleeding pattern: $n=18 \quad(81.8 \%)$ patients presented with complaints of menorrhagia) $\mathrm{n}=2(9.1 \%)$ patients presented with polymenorrhea. $n=1 \quad(4.5 \%)$ patients presented with oligomenorrhea. $n=1 \quad(4.55 \%)$ patients presented with polymenorrhagia.

Out of $n=153$ patients, only 124 patients were taken up for premenstrual endometrial biopsy. Out of $n=14$ patients, with overt hypothyroidism, (71.45\%) had proliferative endometrium followed by (21.4\%) had simple hyperplasia without atypia and (7.1\%) had secretory endometrium. In subclinical hyperthyroidism, most common endometrial biopsy pattern was proliferative $n=10(58.8 \%)$, followed by secretory $n=5$ (29.4\%). In hyperthyroidism, proliferative and secretory pattern were seen in equal number of cases. 
Table 5: Correlation of menstrual pattern in patients with thyroid dysfunction.

\begin{tabular}{|llllll|}
\hline Menstrual problems & $\begin{array}{l}\text { Overt } \\
\text { hypothyroidism }\end{array}$ & $\begin{array}{l}\text { Subclinical } \\
\text { hypothyroidism }\end{array}$ & $\begin{array}{l}\text { Hyperthyroidism } \\
\text { Euthyroid }\end{array}$ & Total \\
\hline Menorrhagia & $13(92.9 \%)$ & $18(81.8 \%)$ & $1(50.0 \%)$ & $99(86.1 \%)$ & $131(85.6 \%)$ \\
\hline Polymenorrhea & $1(7.1 \%)$ & $2(9.1 \%)$ & $0(0 \%)$ & $8(7.0 \%)$ & $11(7.2 \%)$ \\
\hline Oligomenorrhea & $0(0 \%)$ & $1(4.5 \%)$ & $1(50 \%)$ & $7(6.1 \%)$ & $9(5.9 \%)$ \\
\hline Polymenorrhagia & $0(0 \%)$ & $1(4.5 \%)$ & $0(0 \%)$ & $1(0.9 \%)$ & $2(1.3 \%)$ \\
\hline Total & 14 & 22 & 2 & 115 & 153 \\
\hline
\end{tabular}

Table 6: Correlation of endometrial histopathology in abnormal uterine bleeding with thyroid dysfunction.

\begin{tabular}{|llllll|}
\hline $\begin{array}{l}\text { Endometrial } \\
\text { histopathology }\end{array}$ & $\begin{array}{l}\text { Overt } \\
\text { hypothyroidism }\end{array}$ & $\begin{array}{l}\text { Subclinical } \\
\text { hypothyroidism }\end{array}$ & Hyperthyroidism & Euthyroid & Total \\
\hline $\begin{array}{l}\text { Cystic glandular } \\
\text { hyperplasia }\end{array}$ & $0(0 \%)$ & $0(0 \%)$ & $0(0 \%)$ & $1(1.1 \%)$ & $1(0.8 \%)$ \\
\hline $\begin{array}{l}\text { Proliferative } \\
\text { endometrium }\end{array}$ & $10(71.4 \%)$ & $10(58.8 \%)$ & $1(100 \%)$ & $78(85.7 \%)$ & $99(79.8 \%)$ \\
\hline $\begin{array}{l}\text { Secretory } \\
\text { endometrium }\end{array}$ & $1(7.1 \%)$ & $5(29.4 \%)$ & $1(50 \%)$ & $12(13.2 \%)$ & $19(15.3 \%)$ \\
\hline $\begin{array}{l}\text { Simple hyperplasia } \\
\text { without atypia }\end{array}$ & $3(21.4 \%)$ & $2(11.8 \%)$ & $0(0 \%)$ & $0(0 \%)$ & $5(4 \%)$ \\
\hline Total & 14 & 17 & 2 & 91 & 124 \\
\hline
\end{tabular}

\section{DISCUSSION}

In this study, abnormal uterine bleeding was found to be common in age group of 31-40 years, $\mathrm{n}=70(45.8 \%)$ followed by $>41$ years age group $n=60(39.2 \%)$. Usharani $\mathrm{N}$ et al, reported, AUB was more common in the age group of 31-40 years (46\%) followed by age group of 4150 years $(33 \%){ }^{7}$ Sruthi $\mathrm{T}$ et al, most of the patients with thyroid disorders belonged to the age group of 30-40 years $(42 \%) .{ }^{8}$ In the present study it was observed that, menorrhagia was the most common menstrual abnormality ( $85.6 \%$ ) followed by polymenorrhea (7.2\%). In the previous study conducted by Ashok et al similar finding were observed: menorrhagia $(55.26 \%)$ was the most common abnormality followed by polymenorrhoea (7.89\%) Swarupa rani et al and Komathi et al study reported, menorrhagia was most common menstrual abnormality which was $38 \%$ and $72 \%$ respectively. ${ }^{9-11}$ In the present study, thyroid dysfunction was prevalent in $24.9 \%$ patients who had abnormal uterine bleeding, out of which $14.4 \%$ of patients had subclinical hypothyroidism which was the most common thyroid dysfunction, $9.2 \%$ patients had overt hypothyroidism, $1.3 \%$ patients had hyperthyroidism, whereas $75.2 \%$ were euthyroid. In a study conducted by Usharani et al, thyroid disorder was prevalent in $24 \%$ of patients who presented with AUB. ${ }^{7}$ Out of which overt hypothyroidism was found to be $22 \%$ and hyperthyroidism was seen in $2 \%$ patients, while $76 \%$ were euthyroid. In a study conducted by Sangeetha et al, of the total 100 cases diagnosed with abnormal uterine bleeding, $22 \%$ were found to be hypothyroid, $2 \%$ patients were hyperthyroid and the rest were euthyroid $(76 \%) .{ }^{12}$ In a study by Padmaleela et al, thyroid disorders were prevalent in $26.5 \%$ of DUB patients. ${ }^{13}$ Hypothyroidism was seen in $18.1 \%$ and hyperthyroidism in $8.4 \%$, while $73 \%$ of DUB patients were euthyroid. In this study, the prevalence of subclinical hypothyroidism was found to be $14.4 \%$ and overt hypothyroidism was $9.4 \%$, in patients who presented with abnormal uterine bleeding which is comparable to Ghosh $\mathrm{R}$ et al, which had subclinical hypothyroidism in $18 \%$ of the cases and hypothyroidism in $11 \%$ of the cases. ${ }^{14}$ In present study, most common finding in endometrial biopsy was proliferative type 79.8\%. Proliferative pattern $(71.4 \%)$ was common in hypothyroidism patients. Proliferative and secretory pattern were equally common in hyperthyroidism patients. In a study by Sharma $\mathrm{N}$ et al, proliferative pattern was common in both hypothyroidism and hyperthyroidism $36.3 \%$ and $42.84 \%$ respectively. Study done by Rani $\mathrm{S}$ et al, most common finding in endometrial biopsy was proliferative type $63.15 \% .^{10}$ Endometrial biopsy in AUB patients with hypothyroidism shows proliferative type $(63.15 \%)$ followed by secretory type $(26.31 \%)$ and least common type is cystic glandular hyperplasia $(10.52 \%)$.

\section{CONCLUSION}

There is a high prevalence of thyroid disorders in cases which are clinically diagnosed as AUB. The biochemical evaluation of free T3, total T4, TSH are extremely important and valuable. TSH is most sensitive test in detecting thyroid dysfunction. Subclinical cases need to be treated. Hence thyroid function evaluation should be made mandatory in cases of AUB to detect thyroid dysfunction. 
Funding: No funding sources

Conflict of interest: None declared

Ethical approval: The study was approved by the Institutional Ethics Committee

\section{REFERENCES}

1. Padubidri VG, Daftary SN. AUB. In: Padubidri VG, Daftary SN, eds. Shaw's Textbook of Gynecology. $16^{\text {th }}$ ed. USA: Elsevier Health Sciences; 2015:335348 .

2. Bhavani N, Sathineedi A, Giri A, Chippa S, Reddy VSP. A study of correlation between abnormal uterine bleeding and thyroid dysfunction. Int $\mathrm{J}$ Recent Trends Sci Technol. 2015;14(1):131-5.

3. Wilson JR, Beecham CT, Carrington ER. Obstetric and Gynaecology, $5^{\text {th }}$ edn. St. Louis, Mosby; 1975:80

4. Sharma N, Sharma A. Thyroid profile in menstrual disorders. JK Sci. 2012;14(1):14-7.

5. Abraham R, Murugan VS, Pukazhvanthen P, Sen SK. Thyroid disorders in women of Puducherry. Indian J Clin Biochem. 2009;24(1):52-9.

6. Gowri M, Radhika BH, Harshini V, Ramaiaha R. Role of thyroid function tests in women with abnormal uterine bleeding. Int J Reprod Contracept Obstet Gynecol. 2014;3(1):54-7.

7. Usharani N, Kaveri S. Clinical study of hypo/hyper thyroidism in dysfunctional uterine bleeding. Int $\mathbf{J}$ Reprod Contracept Obstet Gynecol. 2017;6(8):33243327

8. Talasila S, Shivanna B, Gopal N. Prevalence of hypothyroidism in patients with provisional diagnosis of Dub. J Evolut Med Dental Sci. 2014;3(11):2967-72.

9. Kumar HSA, Saravanan S. A study of prevalence of thyroid disorders in patients with abnormal uterine bleeding. Int J Reprod Contracept Obstet Gynecol. 2017;6(3):1036-9.

10. Rani AS, Rekha B, Reddy GA, Study of hypothyroidism in women with abnormal uterine bleeding. J Dent Med Sci. 2016;15(4)Ver.VI:12-8.

11. Komathi R, Mallika A, Shantha. A study of thyroid profile in abnormal uterine bleeding (AUB) among reproductive age group women. Int J Current Med Sci. 2016;6(7):133-6.

12. Pahwa, Kaur GA. Thyroid dysfunction in dysfunctional uterine bleeding. JARBS. 2013;5(1):78-83.

13. Padmaleela K, Thomas V, Kiranmai D. Thyroid disorders in dysfunctional uterine bleeding (dub) among reproductive age group women - a crosssectional study in a tertiary care hospital in Andhra Pradesh, India. IJMPS. 2013;4(1):41-6.

14. Ghosh R, Patel RR. Study of association of thyroid disorders with abnormal uterine bleeding. Int $\mathbf{J}$ Reprod Contracept Obstet Gynecol. 2017;6(6):23025 .

Cite this article as: Rai A, Raina S. A study of prevalence of thyroid dysfunction in abnormal uterine bleeding. Int J Reprod Contracept Obstet Gynecol 2020;9:2905-9. 